\title{
Guidelines Stress Collaboration at an Early Stage
}

In presenting for discussion a statement by the International Committee for Future Accelerators (ICFA) to the fourth ICFA Seminar on Future Perspectives in High-Energy Physics, V. Soergel, until recently DirectorGeneral of Germany's national accelerator facility DESY, commented that any future large-scale accelerator project such as a TeV-class linear collider would not be acceptable to governments without the prior agreement within the particle physics community on technical parameters and a site. Speaking at the meeting which was held in Hamburg on 3-7 May at DESY, he saw the guidelines for international collaboration spelt out in an ICFA statement issued at the seminar as an important step in tackling what B. Richter, the Director of SLAC in California, felt was the most important aspect, namely "how to do things with the maximum efficiency".

ICFA is a 15-person committee comprising the Directors of major high-energy physics laboratories; the present Chairman is $\mathrm{J}$. Peoples, the Director of Fermilab in the USA. It was set up by the International Union of Pure and Applied Physics (IUPAP) Particles and Fields Commission in 1976. The aims as redefined in 1985 are to promote international collaboration during the construction and exploitation of very-high energy accelerators, and to advise and exchange information on plans for regional facilities.

The statement, while largely reiterating the aims, nonetheless clearly indicates that collaboration must start at the early stages of future large-scale facilities, defined as those with a unique scientific potential of which only one should exist in a given field. Such facilities should be planned, designed and where appropriate built, by an international collaboration. Moreover, R\&D should be carried out on an international basis before construction, and should be open to all countries and potential participating institutions on equal terms.
An agreement on an appropriate structure to review a scientific proposal for a facility by the scientific community should be set up before making formal approaches to governments. Governments, meanwhile, must be kept informed of progress

The four models for collaboration identified by ICFA are:

- National or regional facilities built and operated by a host country where planning and the choice of parameters should be done internationally.

- Large facilities needing outside funding along the lines of the model used to build DESY's HERA $\mathrm{e}^{+} \mathrm{e}^{-}$collider.
- Large projects requiring collaboration between several countries, with comparable shares from each to cover both construction and operating costs. In this case the facility would be common property regulated by government agreements.

- Very large projects built and operated within the framework of an international organization such as CERN.

Other ideas for promoting collaboration which arose during the discussion ranged from avoiding a bureaucratic overhead (A Skrinsky, Director, Institute for Nuclear Physics, Novosibirsk, Russia) to maximizing the advantages to non-host countries to ensure a stable framework (S. Wojcicki, SLAC). Several felt there was a need to promote construction at, or under the auspices of, existing centres to reduce costs and to relieve the pressure on existing labs, something that is acutely felt by the particle physics community in the USA while the SSC collider is being built in Texas.

\section{World Linear Collider R\&D Agreement Endorsed}

The world now has at the Stanford Linear Collider Center (SLAC) in California an $\mathrm{e}^{+} \mathrm{e}^{-}$ linear collider which is running routinely as a high-energy physics machine. More than 700 $Z^{\circ}$ particles will be produced each day this year and upgrading means that the luminosity should more than double from today's value by the end of 1994 (to $25 \%$ of the design value).

R. Siemann from SLAC speaking at the ICFA Seminar in Hamburg on 5 May described other "dramatic changes in the prospects for linear colliders". There has been considerable progress these last 10 years on specific components, and a number of prototype and test facilities are being set up (see p. 84).

There are some negative aspects. Discussions are presently focussed on a 0.5 $\mathrm{TeV} \mathrm{e}^{+} \mathrm{e}^{-}$machine instead of the 1-2 $\mathrm{TeV}$ considered when the SSC and LHC hadron colliders were being planned. But the time- scale is optimistic as one must wait for the results from prototypes; it may even be beyond "human time-scales" if one waits for results from the large hadron colliders. The main questions are therefore:

- Is a $0.5 \mathrm{TeV}$ machine an end in itself or a stop along the way?

- Are superconducting linacs suitable for the $\mathrm{TeV}$ range?

- Will a technically conservative $0.5 \mathrm{TeV}$ collider say enough about construction and operation at multi-TeV energies?

U. Amaldi (CERN) commented during a general discussion on $\mathrm{e}^{+} e^{-}$colliders that $1-2$ $\mathrm{TeV}$ should be the long-term goal, $0.5 \mathrm{TeV}$ is not a compromise as the physics case is strong, and there are good synergies with the large hadron colliders. B. Richter (SLAC) felt that while "any energy should be a stop along the way", from the machine builders' point of view, the only linear collider that exists is "an

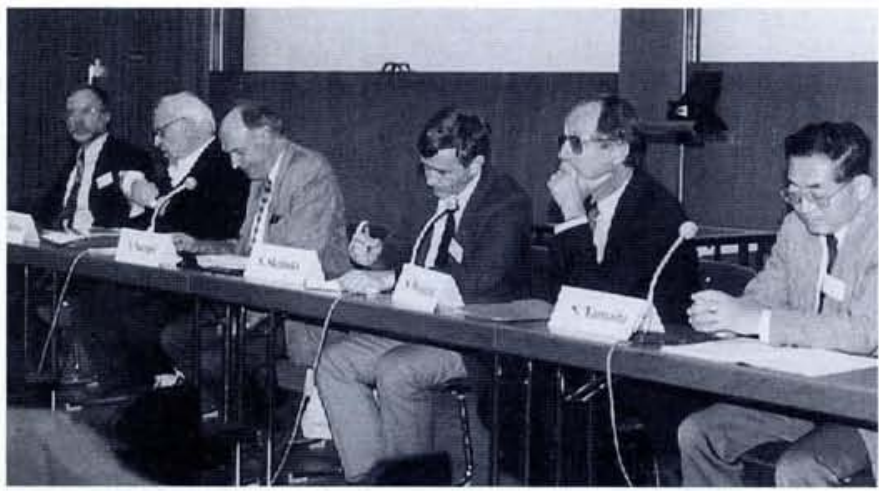

The International Committee for Future Accelerators (ICFA) panel on international collaboration at the ICFA Seminar on Perspectives in High-Energy Physics, Hamburg, 3-7 May 1993. From the left: G Flügge (Aachen; European Committee for Future Accelerators), B. Richter (Director, Stanford Linear Accelerator Center), V. Soergel (Member, DESY Scientific Council), A. Skrinsky (Director, INP, Novosibirsk), S. Wojcicki (Stanford; IUPAP), and S. Yamada (Tokyo).

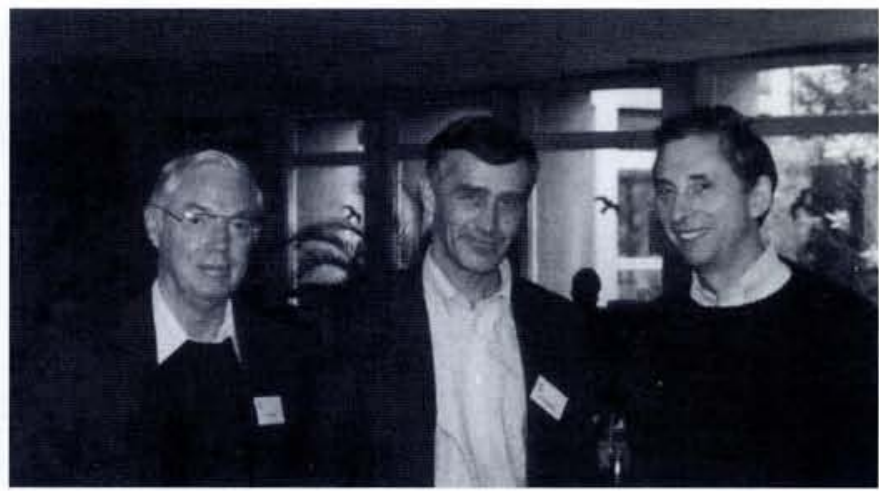

From the left, W.O. Lock, A. Skrinsky and J. Peoples. Owen Lock, who retired from CERN last year, was the Secretary of ICFA for 15 years. $\mathrm{He}$ is succeeded by R. Rubinstein from the Fermi National Accelerator Laboratory (Fermilab), Michigan, USA. Alexander Skrinsky, Director, Institute for Nuclear Physics, Novosibirsk, Russia, was succeeded last year as the Chairman of ICFA by John Peoples, the Director of Fermilab. 
old car" and the equivalent of 40 years of experience with synchrotron machines is lacking. Some "learning is needed and most feel the threshold is $0.5 \mathrm{TeV}^{\prime \prime}$.

\section{Trade-Offs}

Siemann argued that decisions will depend upon judgments about the ease of technology improvements, cost reductions, extension to higher energies, background levels and centre-of-mass energies at high-energy physics experiments, and tolerances and beam power. Trade-offs are required. For example, high aspect ratio "flat" beams minimize backgrounds. Luminosity is then proportional to $f P_{\mathrm{B}} / \sigma$ for a frequency $f$, beam power $P_{\mathrm{B}}$ and transverse beam size $\sigma$. Assuming that $f$ is essentially determined by engineering and technical considerations, luminosity maximization implies trading off $P_{\mathrm{B}}$ and $\sigma$. This is because increasing the power places greater demands on the machine while reducing $\sigma$ calls for tight tolerances and accurate beam corrections.

Some groups argue that for stability, the energy extracted from the bunch in a multibunch beam must be small compared to the stored energy in the bunch W. As W $\sim f^{-2}$ one expects that the difficulty to preserve the beam emittance will be proportional to $f^{2}$. They therefore favour low-frequency approaches, notably the room-temperature S-band and the superconducting TESLA designs. Only experimentation can decide, hence the importance of the prototypes and test beds - and of the R\&D collaborations that go with them.

\section{Structuring Collaboration}

Informal R\&D collaboration for a future linear $\mathrm{e}^{+} \mathrm{e}^{-}$collider started in 1986. B. Richter felt "the time has now come to take the next step" by creating a more formal structure with the aim of coming up with a proposal for a major linear collider based on a "genuine inter-regional facility". A Memorandum of Understanding (Mol) for a Linear Collider World Collaboration has been drafted for

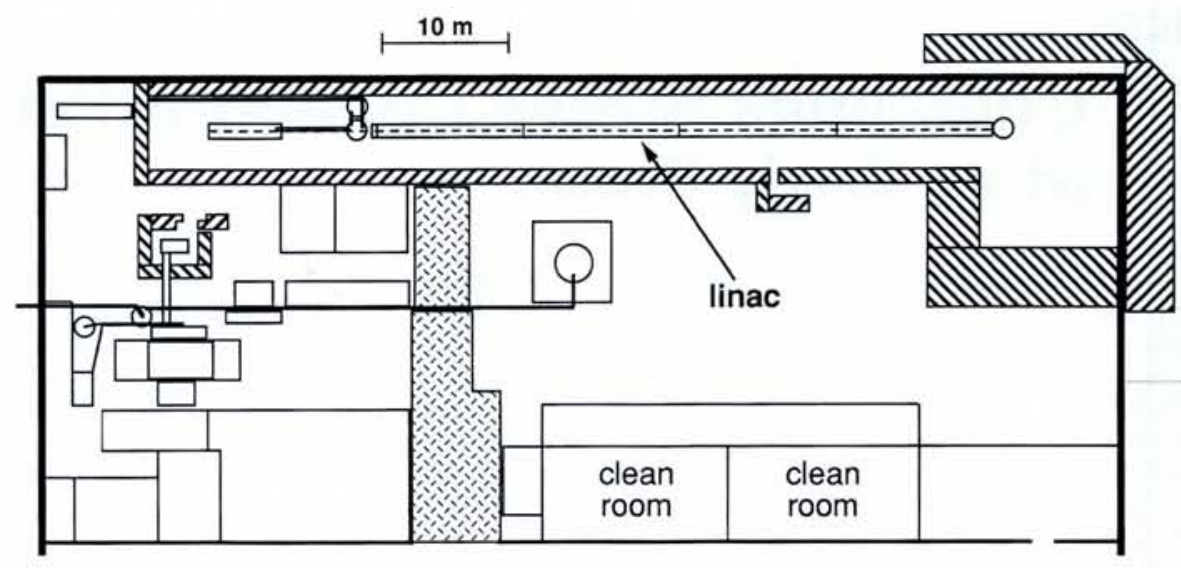

A plan for the $400 \mathrm{MeV}, 3 \mathrm{GHz}$ TESLA Test Facility under construction at DESY in Hamburg The $65 \mathrm{~m}$ long test device with its injector, spectrometer, and linear accelerator comprising four cryomodules each containing a superconducting 8-cell RF cavity will be housed inside a shielding enclosure in Hall 3.

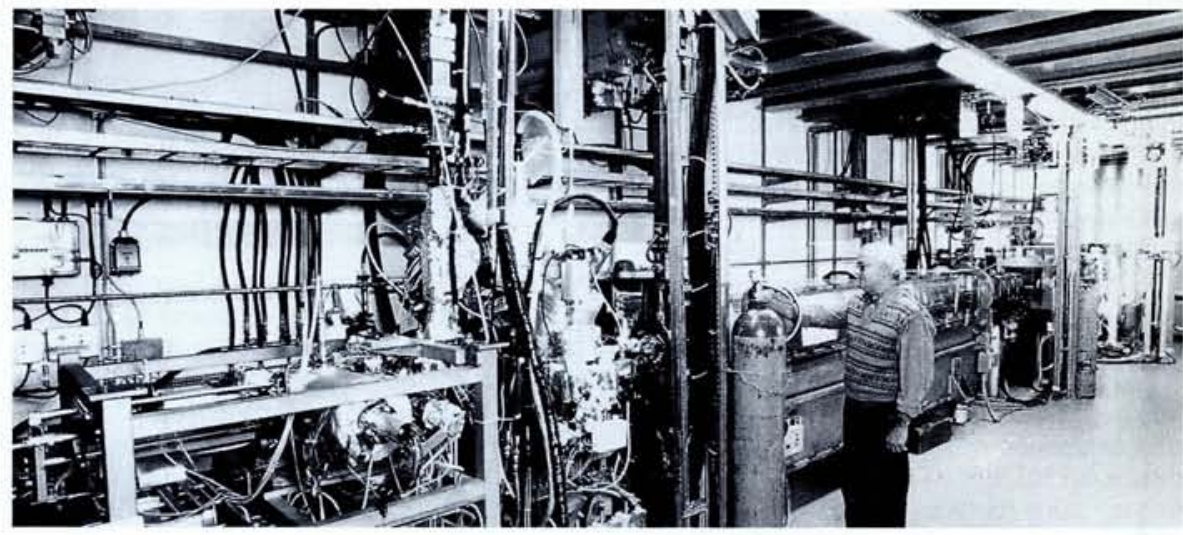

The CLIC Test Facility (CTF) at CERN. The $3 \mathrm{GHz}$ injector with its RF gun and a laser triggered photocathode is in the foreground and the major part of the central section comprises the 3 $\mathrm{GHz}$ accelerator. A prototype of the CLIC accelerating structure is mounted at the end. Extensions in progress include a CLIC accelerating structure parallel to the first (deaccelerating) structure to test the two-beam drive concept. CTF successfully generated in late-1992 some $2.7 \mathrm{MW}$ of $30 \mathrm{GHz}$ pulsed power with a $60 \mathrm{MeV}$ beam of a train of eight electron pulses.

Preliminary parameters and test facilities/prototypes for proposed linear colliders for a centre-of-mass energy of $500 \mathrm{GeV}$.

\begin{tabular}{|c|c|c|c|c|c|c|}
\hline Proposal & TESLA & S-band & NLC & JLC & VLEPP & CLIC \\
\hline host lab & DESY & DESY & SLAC & KEK, Tsukuba & INP, Protvino & CERN \\
\hline frequency, $\mathrm{GHz}$ & & 3.0 & 11.4 & $2.8-11.4$ & 14 & 30 \\
\hline regime & \multirow{2}{*}{\multicolumn{2}{|c|}{$\begin{array}{l}\text { superconducting } \\
\text { multicell RF cavity }\end{array}$}} & & & & \\
\hline accelerating sructure & & & \multicolumn{2}{|c|}{ Cu multicup structure } & & \multirow{3}{*}{$\begin{array}{l}\text { novel } \\
\text { two-beam } \\
\text { (2) }\end{array}$} \\
\hline $\begin{array}{l}\text { type } \\
\text { RF power supply }\end{array}$ & & advanced & $\begin{array}{l}\text { conventional } \\
\text { klystrons }\end{array}$ & conventional & conventional & \\
\hline no. of klystons & $1264(+)$ & 2450 & 1945 & $1735-3400$ & 1300 & \\
\hline power conversion eff., \% & $12(+)$ & 7 & 3 & 2 & 3 & 1 \\
\hline beam power, MW & $16.5(+)$ & 7.5 & 4.2 & $1.6-3.8$ & 2.4 & $0.4-1.6$ \\
\hline horo./vert. beam sizes, $\mu \mathrm{m}$ & $640 / 100$ & $400 / 32$ & $300 / 3$ & $280 / 3$ & $2000 / 4$ & $90 / 8(-)$ \\
\hline $\begin{array}{l}\text { gradient, MV/m } \\
\text { gradient limits }\end{array}$ & $\begin{array}{l}25 \\
\text { important (-) }\end{array}$ & $\begin{array}{l}21 \\
\text { important (-) }\end{array}$ & 50 & $22-40$ & 108 & 80 \\
\hline section length, m & 1.0 & $6(+)$ & 1.8 & $1.2-3.6$ & 1.0 & 0.3 \\
\hline Test facility & TTF & S-Band TF & NLCTA & JLC-ATF & VLEPP-ATF & CTF \\
\hline components & \multicolumn{3}{|c|}{$\longrightarrow$ injector + accelerator + spectrometer -} & $\begin{array}{l}\text { 1st part of } \\
\text { proposed JLC }\end{array}$ & $\begin{array}{l}\text { injector + } \\
\text { accelerator + } \\
\text { spectrometer }\end{array}$ & $\begin{array}{l}\text { injector }+ \\
\text { accelerator + } \\
\text { test accelerators* }\end{array}$ \\
\hline energy, MeV & 500 & 400 & 540 & 1540 & 500 & 80 \\
\hline no. of klystons & 2 & 2 & 3 & 10 & 3 & - \\
\hline active length, $\mathrm{m}$ & 32 & 24 & 11 & - & 5 & 8 \\
\hline total length, m & 65 & 45 & 35 & - & 40 & 10 \\
\hline status & opern.: 1996 & opern.: 1996 & complete: 1996 & opern.: 1995 & 1st test: 1993 & opern.: 1990 \\
\hline
\end{tabular}

Notes: positive (+) and negative (-) features; * deceleration followed by reacceleration 


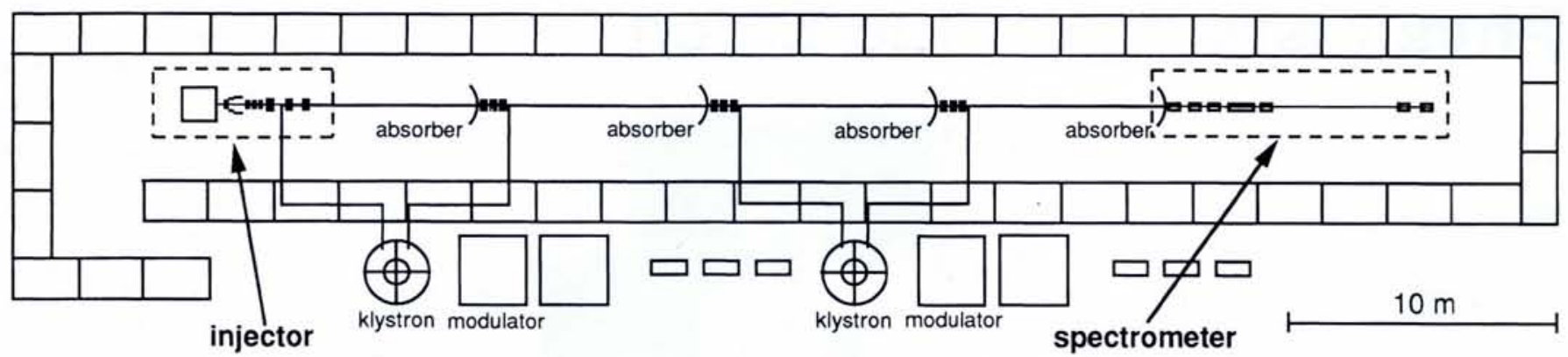

A plan of the $45 \mathrm{~m}$ long $400 \mathrm{MeV} \mathrm{S}$-Band Test Facility under construction in Hall 2 at DESY, Hamburg.

signing by the main laboratories participating in linear collider R\&D (essentially SLAC, DESY, CERN, Japan's national high-energy physics facility KEK, and the Institute of Nuclear Physics based in Novosibirsk and Protvino in Russia). The Mol envisages a democratically elected Collaboration Council composed of institute representatives reporting to a Regional Council. The most important feature of the scheme for the immediate future may be the technical review groups reporting to the Collaboration Council as they provide a mechanism for reflecting upon, and ultimately choosing between, the various technical options.

J. Peoples, the ICFA Chairman, says ICFA plans to issue a statement endorsing the memorandum within the context of the guidelines on international collaboration - an illustration of the sort of rôle ICFA has in helping steer the high-energy accelerator community into the next century.

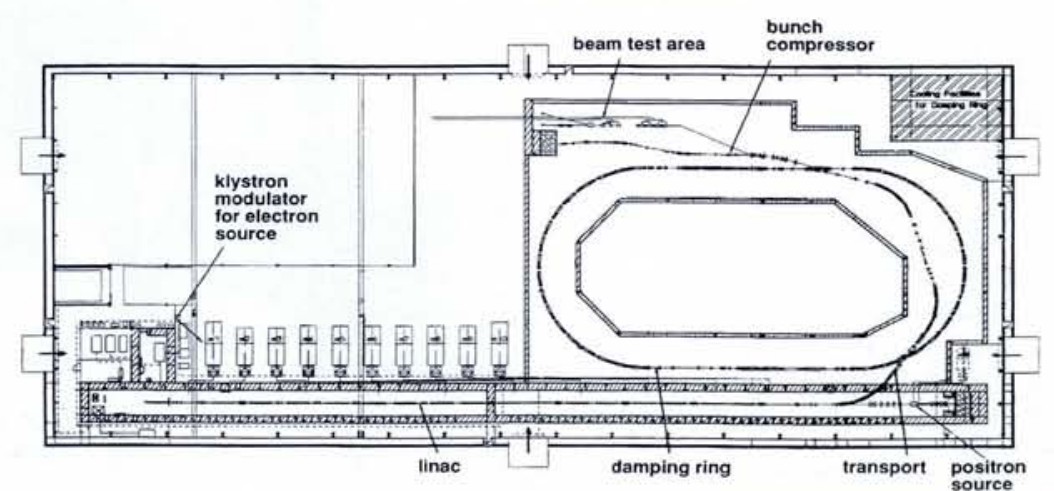

A plan of the $50 \times 120 \mathrm{~m}$ Japan Linear Collider - Accelerator Test Facility (JLC-ATF) under construction at the Japanese National Laboratory for High-Energy Physics (KEK) in Tsukuba. JLC-ATF, comprising an injector, linac, damping ring, and final focus test area, is basically the first stage of JLC-1, a proposed 300-500 GeV linear collider being designed for physics experiments in about 2001 (funding has yet to be approved and choosing the linac frequency will take 2-3 years).

\section{Summary of Some Principle Linear Collider R\&D Actifivities}

TESLA Test Facility (operation planned for 1996; DESY)

infrastructure

- construction of clean room started for treatment \& assembly of multicell RF cavities into cryomodules; 3 cryostats + cavity treatment furnace in place

accelerator structure

- 2 multicell cavities ordered

- high-power processing (HPP) of cavities to minimize breakown under development (Cornell, CEBAF, Saclay, FNAL)

- proof-of-principle of TESLA cavity shape at $1.3 \mathrm{GHz}$ in hand using a 2-cell cavity with HPP

S-band Test Facility (operation planned for 1996; DESY)

infrastructure

accelerator structure

klystron

modulators

- under construction

- prototype being designed

- upgraded klystron ready in 1994 (SLAC)

- standard type to be installed; switch tube for a novel type tested in 1993 ready for modulator test in 1994

Next Linear Collider Test Facility (SLAC, California; completion in 1996)

infrastructure

accelerator structure

klystron

modulator

pulse compressor

Final Focus Test Facility

- under construction

- $0.3 \mathrm{~m}$ section tested; $0.75 \mathrm{~m}$ section to be tested in 1993; full $1.8 \mathrm{~m}$ prototype ready in 1993

- tests of a section in the Stanford Linear Collider foreseen (ASSET Facility)

- prototype of upgrade available in 1993

- prototype under construction

- low-power tests complete; high-power tests of prototype in 1993

- first beam test with SLC in June

- $\mathrm{e}^{-}$beam-laser beam interaction experiment approved

CLIC Test Facility (operating; CERN)

accelerator structure

two-beam system test

transfer structure

pulse compressor

beam positioning
-2 built; 1 under construction; scaled-up section tested at KEK

- reaccelerator section to follow deaccelerator section being installed

- prototype under construction

- model tested

- prototype monitors made

- Beam Alignment Test Facility being extended to $8 \mathrm{~m}$ to handle four accelerator sections

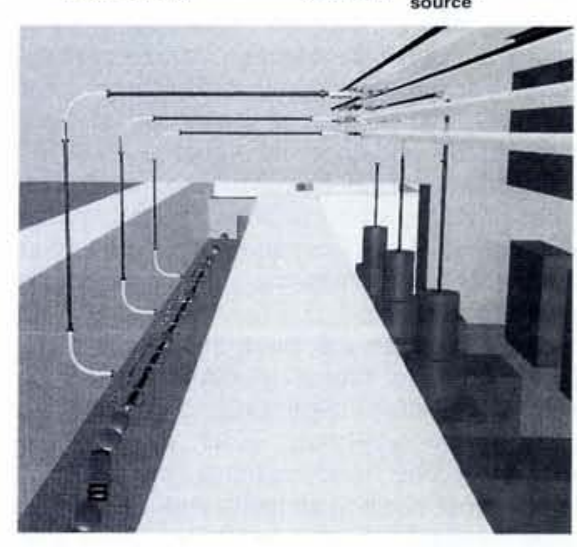

A simulated view inside the shielding enclosure for the Next Linear Collider Test Accelerator (NLCTA) at SLAC. Planning allows an eventual upgrade from $540 \mathrm{MeV}$ to 1080 $\mathrm{MeV}$ by doubling the number of klystons and the length of the accelerating structure.

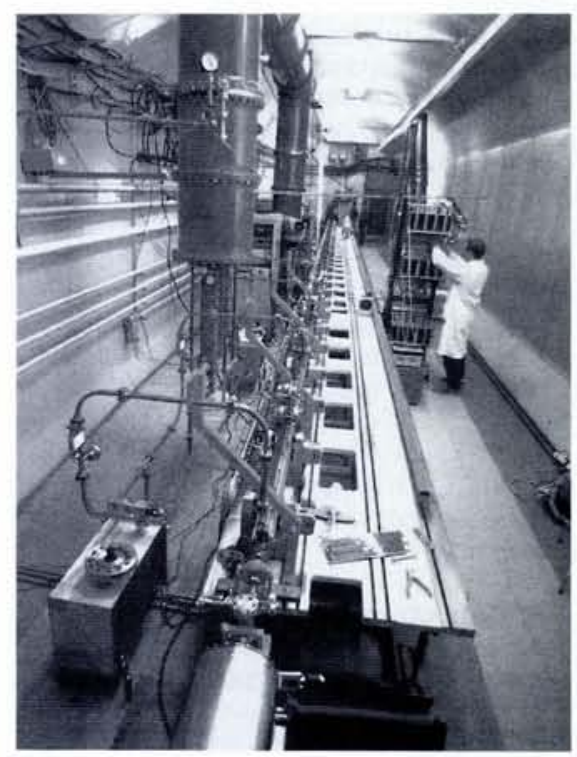

The test bed at INP, Protvino, for components to test the accelerating structure of the proposed VLEPP linear collider. 